East African Medical Journal Vol. 80 No. 12 December 2003

PREVALENCE OF ROTAVIRUS, ADENOVIRUS AND ASTROVIRUS INFECTION IN YOUNG CHILDREN WITH GASTROENTERITIS IN GABORONE, BOTSWANA

G. Basu, BSc, (Lucknow, India), MSc, P.O. Box 2327, Gaborone, Botswana, J. Rossouw, BSc (Hons), MSc, MRC Diarrhoel Path Research Unit, Pretoria, South Africa, T.K. Sebuya, BVM (Nairobi), MSC, PhD (Saskachewan), B. A. Gashe, BSc, (AAU), MSc, PhD (Oklahoma), Universitry of Botswana, Department of Biological Sciences, Private Bag UB 00704, M. de Beer, MSc (Med), J. B. Dewar, BSc, (Hons), MSc, PhD., and A.D Steele, BSc (Hons), MSc, PhD, MRC Diarrhoel Path Research Unit, Pretoria, South Africa

Request for reprints to: Dr. T.K. Sebunya, University of Botswana, Department of Biological Sciences, Private Bag UB 00704, Gaborone, Botswana

\title{
PREVALENCE OF ROTAVIRUS, ADENOVIRUS AND ASTROVIRUS INFECTION IN YOUNG CHILDREN WITH GASTROENTERITIS IN GABORONE, BOTSWANA
}

\author{
G. BASU, J. ROSSOUW, T.K. SEBUNYA, B.A. GASHE, M. DE BEER, J.B. DEWAR and
} A.D. STEELE

\begin{abstract}
Objective: To determine the prevalence of three enteric viruses, namely rotavirus, adenovirus and astrovirus, as agents of diarrhoea in and around Gaborone, Botswana. Design: The sample were categorised into four groups according to the age of the patient: 0-3 months, 4-6 months, 7-12 months and 25-60 months. Total monthly samples across age groups formed basis for calcultating seasonal prevalence of rotavirus infection. Setting: Stool samples were collected from three medical laboratories in Gaborone and one in the town of Mochudi. These were collected from children under the age of five years with gastroenteritis.

Subjects: Stool samples were collected between March 2001 and February 2002 from 346 children less than five years of age suffering from gastroenteritis. These samples had been sent to medical laboratories for microbiological examination.

Methods: The samples were screened for rotavirus (RV), adenovirus (Ad) and astrovirus (AsV) antigens using commercially available ELISA kits. The Ad positive samples were further analysed by commercially available group specific Ad type 40/41 Enzyme Immuno Assays (EIA).

Results: Shedding of RV was detected in $9.2 \%$, Ad in $7.8 \%$ and $\mathrm{AsV}$ in $2.7 \%$ of the samples analysed. The enteric Ad (types 40 and 41) were detected in $2 \%$ of the samples and the remaining $5.8 \%$ of Ad positive samples were non-enteric Ad. An increase of $R V$ was noted in the autumn-winter season but no seasonal pattern was observed in Ad shedding. Seasonal prevalence of AsV could not be determined. The average age of children infected with these agents was less than one year.

Conclusion: The incidence of rotavirus infection amongst children in Botswana appears to be relatively low. The prevalence rate of adenovirus and astrovirus is similar to other studies in parts of Southern Africa. However, continued enteric virus surveillance and epidemiology amongst this group is required.
\end{abstract}

\section{INTRODUCTION}

Diarrhoeal diseases affect millions of people around the world and have the greatest impact on children, especially those in developing countries. Almost every child contracts a diarrhoeal disease during the first five years of their life, on an average several times per year (1). Diarrhoea is one of the leading causes of death in developing countries, responsible for $25-30 \%$ of deaths among children younger than five years of age $(2,3)$. In these countries the incidence of diarrhoeal cases varies between 2.5-3.9 episodes per child per year. In Africa, about 2.5 episodes per child per year are reported mainly among children between 6-11 months of age, corresponding to the introduction of weaning foods(1).
Diarrhoea can be caused by a number of different agents, including viruses, bacteria, parasites and toxins. However, during the past two decades, viruses have been firmly established as aetiological agents of acute gastroenteritis (GE)(1). There are four major virus groups aetiologically linked to diarrhoea ; rotavirus, astrovirus, adenovirus and calicivirus(1). In both developed and developing countries, rotavirus is responsible for the greatest proportion of severe childhood diarrhoea(1).

In Botswana, a high incidence of childhood diarrhoea accounts for $8-12.5 \%$ of all deaths in children less than five years of age(4). In this age group the estimated mean number of episodes of diarrhoea are 3.2 per child per year. However, in children below one year of age this number increases to 4.5 per child per 
year. In addition, within the past 14 years there has been a $40 \%$ increase in diarrhoeal cases, increasing from $1959 / 10,000$ episodes in 1983 to $2756 / 10,000$ episodes in 1999(6).

Very few studies have been performed in Botswana to determine the aetiological agents of diarrhoeal diseases. General laboratory analysis in referral hospitals and clinics mainly report Shigella, a bacterial agent, as the causative agent of diarrhoea(1). Thus, most diarrhoeal cases (30-70\%) are not aetiologically elucidated, particularly those linked to virus infection (5). Studies by Tlagae(7) and BIDPA(4) concentrated on diarrhoea incidences and risk factors. Recently Urio et al.,(8) carried out a study on Shigella and Salmonella strains where they isolated Shigella from 43/221 (21\%) and Salmonella from 8/221 (3\%) of rectal swabs from children under five years of age with diarrhoea. However, studies by Sebunya et al.(9) and Kasule(10) have confirmed rotavirus as an important viral agent causing diarrhoea (about 17\%) in children below five years of age. Hence, there is a need to establish the contribution of enteric viruses associated with diarrhoeal disease in Botswana. This will add to the data on viral diarrhoeal agents in sub-Saharan Africa. This study looks into the prevalence of three viral agents of diarrhoea, namely rotavirus, astrovirus and adenovirus, in children less than five years of age in Gaborone and surrounding areas.

\section{MATERIALS AND METHODS}

Location of Study: This study was conducted in Gaborone city and in Mochudi, a town $32 \mathrm{~km}$ from Gaborone. These two sites were chosen as they cover two health districts in Botswana; namely the Gaborone district and the Kgateleng district respectively. The samples were collected from four laboratories: The National Health Laboratory (Gaborone); Gaborone Private Hospital Laboratory; Diagnofirm Laboratory (Gaborone) and Deborah Retif Memorial Hospital Laboratory (Mochudi).

Specimen Collection: A total of 346 stool samples were collected from March 2001 to February 2002 from children less than five years of age presenting with gastroenteritis. These samples were sent for microbiological screening at the pathology laboratories. The samples were collected in sterile specimen collection bottles and transported to the University of Botswana in iceboxes and stored in the cold-room (5$10^{\circ} \mathrm{C}$ ). Each sample was then diluted to $10 \%$ with sterile distilled water and stored at $4^{\circ} \mathrm{C}$.

ELISA Detection of Rotavirus, Astrovirus and Adenovirus antigens: The presense of viruses in stool samples was determined using enzyme immunoassay (EIA) according to the manufacturer's protocols. Results were interpreted against controls included in each plate. Group A rotaviruses and astroviruses were detected using commercial ELISA kits (IDEA $^{\mathrm{TM}}$ ) Rotavirus or Astrovirus, DAKO Ltd., Denmark House, Germany). Adenoviruses were screened using a commercial ELISA (Ridascreen Adenovirus, R-Biopharm, Germany). Adenovirus positive samples were subjected to further screening for the enteric adenovirus types 40 and 41 with a species specific EIA (Premier Adenoclone ${ }^{\circledR}$ Type-40/ 41 EIA (Meridian Biosciences).

\section{RESULTS}

All of the 346 children with GE were screened for rotaviruses and adenoviruses while only 219 of these were screened for astroviruses. The incidence of rotavirus infection was the highest at $9.2 \%$ (32/346). Non-enteric adenoviruses were detected in $5.8 \%$ (20/ $346)$ and enteric adenoviruses were detected in $2 \%$ (7/ $346)$, while astroviruses were detected in $2.7 \%(6 / 219)$ of the stool samples (Figure 1).

Figure 1

Incidence of enteric virus infection in children less than five years of age with gastroenteritis

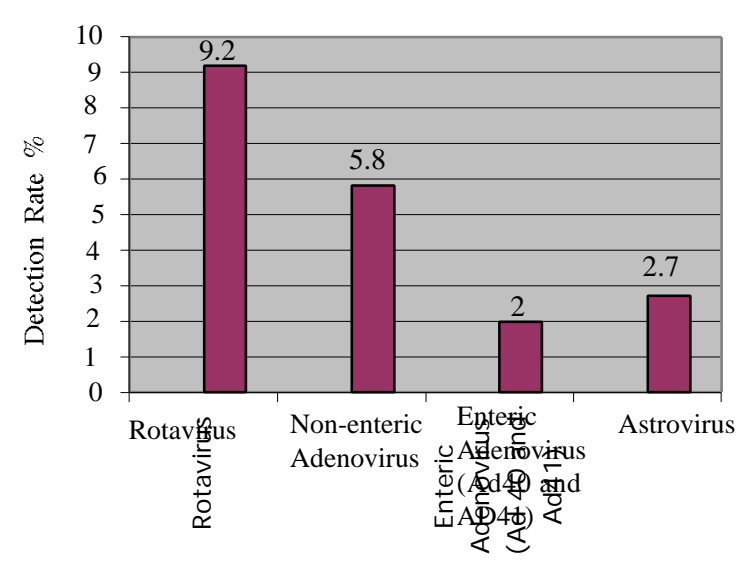

The figure shows the detection rate in percentage of rotavirus, nonenteric adenovirus, enteric adenovirus (Ad 40 and Ad41) and astrovirus in children less than five years of age suffering from gastroenteritis.

\section{Figure 2}

Comparative infection rates of rotavirus, adenovirus (enteric and non-enteric) and astrovirus in children less than five years of age

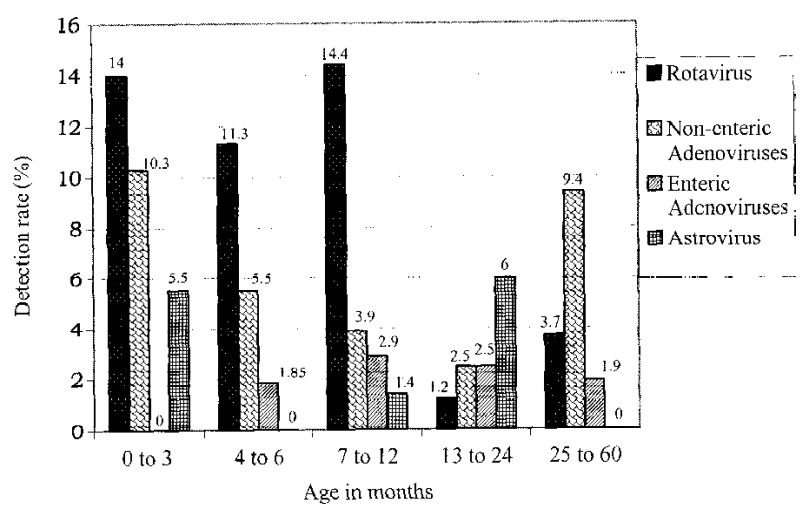

The figure shows the comparative infection rates of rotavirus, adenovirus (enteric and non-enteric) and astrovirus in children less than five years of age suffering from gastroenteritis. 
Figure 3

\section{Monthly distribution of rotavirus and adenovirus} (enteric and non-enteric) infection

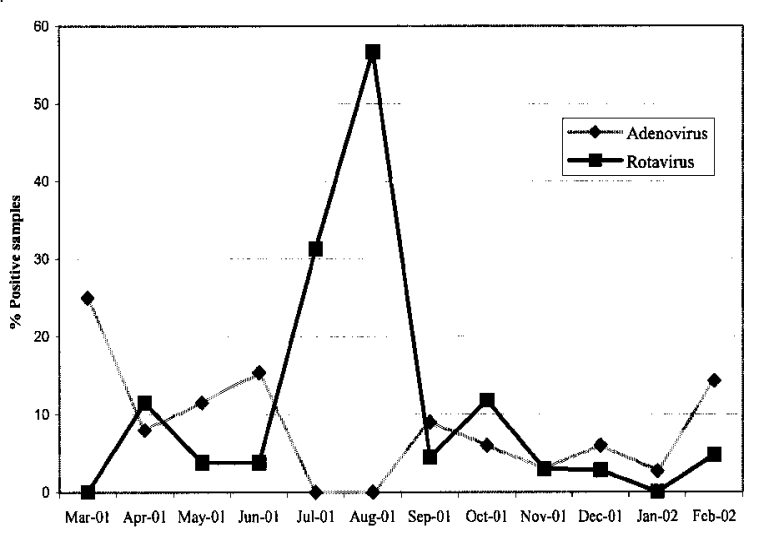

The figure shows the monthly distribution of the rotavirus and adenovirus positives that were detected over the period of 12 months from March 2001 to February 2002.

The age distribution and virus detection rate is shown in Figure 2. From this data, the mean ages of infection in children less than five years of age for rotavirus, non-enteric adenovirus, enteric adenovirus and astrovirus were determined to be 9.7, 16.8, 16 and 11.3 months respectively.

Rotavirus and adenovirus infections appear to occur all year round with a distinct peak in rotavirus infection during autumn and the cool dry winter season (June to August) (Figure 3). Adenovirus infection was slightly more during the first half of 2001.

\section{DISCUSSION}

In this study, group A rotaviruses were detected in $9.2 \%$ of the stool samples of children less than five years with GE. This figure is much lower than the published median rate of $24 \%$ (reviewed in 43 published studies of rotavirus epidemiology in Africa)(11). This 12-month survey of enteric virus infection in and around Gaborone indicates that rotaviruses were circulating within the community throughout the year, with infection peaking in the cooler and drier months of July (31.25\%) and August $(56.7 \%)$. These results are in accordance with the other studies conducted in Botswana by Sebunya et al.(9) and Kasule(10). These results also support other southern American studies from Zambia, Zimbabwe and South Africa(11). Published data indicated that the highest rotavirus prevalence rates occurred in children aged 618 months with severe infections occurring more frequently in younger children aged 6-12 months in developing countries(12). In addition, infection often occurs in children less than three months of age $(13,14)$. In this study, the majority of the rotavirus infections (91\%) were observed in children less than two years of age, emphasising the fact that rotavirus infection occurs early in life. It is reported that multiple rotavirus infection is common during the first two years of life.

A Venezualan study by Perez-Schael et al.(15) reported the generation of rotavirus-specific IgA antibodies following rotavirus infection. By the age of 11 months about $85 \%$ of the infants had acquired rotavirus IgA antibodies. Neutralising IgG antibodies also increased markedly as the children reached a year in age, reflecting exposure to natural infection. As expected, infection in this age group is generally mild, with few deaths reported worldwide. In the present study, a low prevalence to rotavirus was noted in older children between 2 to 5 years of age $(3.7 \%)$. This could be explained by the acquisition of neutralising antibodies to rotavirus early in life as a result of multiple exposures to rotavirus infection.

Adenoviruses were detected in 27/346 (7.8\%) of the samples. These results are comparable to other studies where the incidence of enteric adenoviruses was reported as: $6.5 \%$ in South Africa (20), 6.7\% in Iran (21) and $13 \%$ in Mexico (22). These figures are high in comparison to other reports from Brazil at $1.55 \%$ (16), $3.1 \%$ in Australia (17), 3\% in South Africa (18) and 3\% in France (19). Most of the adenovirus positives $(77.7 \%)$ were detected from children less than two years of age. Majority of the adenoviruses detected were non-enteric ones $(5.8 \%)$ while only $2 \%$ of the detected adenoviruses were enteric adenoviruses (type Ad40 and Ad41). Most of the non-enteric adenoviruses were detected in children less than three months of age and in older children between 25 to 60 months. Non-enteric adenoviruses, like Adl2, Adl8 and Ad31 (sub-species A), have a tropism for the alimentary canal and have been reported to cause diarrhoea, mainly in children(23). They may also represent the strains responsible for respiratory infections. As a systemic infection, respiratory adenoviruses may also cause diarrhoea(24). It appears that infection with enteric adenoviruses (Ad40 and Ad41) was low in the study group and was not detected in children less than three months of age. Seroprevalence studies have shown that $50 \%$ of children less than four years of age have antibodies to enteric adenoviruses $(16,20)$. This indicates that there is an initial exposure to adenovirus infection in infants and in toddlers.

The prevalence of astrovirus was $6 / 219(2.7 \%)$ of the samples. This is similar to other studies showing an incidence of astrovirus infection in children with GE of $2 \%$ in India (25), 3\% in Brazil(26), 4.2\% in Australia(27). However, in some studies, higher rates of astrovirus infection have also been reported. These include $6.3 \%$ in France (19), 6.8\% in USA (28), and 7\% in South Africa (18). The majority of the astrovirus positive samples $(75 \%)$ were observed in children less than two years of age and no positive cases were found in children over two years of age. In this regard, seroprevalence studies in England reported that by the age of 5 to 10 years, astrovirus antibodies are found in $75 \%$ of the children(29). This suggests that older children may have acquired antibodies against astroviruses early in life due to natural exposure to this virus.

In conclusion, comparison of the detection rates for 
rotavirus, non-enteric adenovirus, enteric adenovirus and astrovirus in these children indicates that rotavirus infection is mainly observed in children under two years of age with the rate of disease declining thereafter. The relatively low prevalence rates of these enteric viruses in children as compared to studies elsewhere in the developing world could be attributed to a relatively low incidence of these viral infections within urban settings, such as Gaborone. Studies are required to confirm the incidence rates of these viral agents within rural communities.

\section{ACKNOWLEDGEMENTS}

This study was supported by grants from the World Health Organisation and the South African Medical Research Council. Technical support was provided by the MRC Diarrhoeal Pathogens Unit, MEDUNSA, South Africa and the Department of Biological Sciences, Univesity of Botswana. We are thankful for all the participating laboratories for their co-operation and help in sample collection.

\section{REFERENCES}

1. Bern, C. J. and Glass, R.I. Impact of Diarrhoeal Diseases Worldwide. In: Viral infections of the gastrointestinal tract, 2nd Edn. A. Z. Kapikian (Ed.), Marcel Dekker, New York. 1994: 1-26.

2. Snyder, J. D. and Merson, M.H. The magnitude of the global problem of acute diarrhoeal disease: a review of the active surveillance data. Bull. Wld. Hlth. Org. 1982; 60:605-613.

3. Martines J., Phillips M., and Feachem R. G. Evolving Health Sector Priorities in Developing Countries. In: Diarrhoeal Diseases, (Eds.) D.T. Jamison and W.H. Mosley. World Bank, Washington D. C. 1991; 1-49.

4. Botswana Institute for Development Policy Analysis (BIDPA), A Preliminary Analysis of the 1996 Botswana Family Health Survey. Gaborone: The Institute. 1998.

5. Ministry of Health Botswana. Health Statistics. The Central Statistics Office, Gaborone, Botswana. 1999.

6. Ministry of Health Botswana; Health Statistics. The Central Statistics Office, Gaborone, Botswana. 1997.

7. Tlagae M. G. Diarrhoeal diseases: a study on the incidence of diarrhoea in under five year children and possible factors that contribute to the incidence. Done at Tlokweng village of South-east District, Botswana. MA (Community Health) Thesis, University of Liverpool. 1991.

8. Urio, E.M., Collison, E.K., Gashe, B.A., Sebunya, T.K. and Mapuchane, S. Shigella and Salmonella strains isolated from children under 5 years in Gaborone, Botswana, and their antibiotic susceptibility patterns. Trop. Med. Int. Hlth. 2001; 6:55-59.

9. Sebunya, T.K., Collison, E., Simpanya, M.F., Ndabambi, N., and Moyo, S. Prevalence of rotavirus in stool samples of children in Gaborone and surrounding areas. Proceedings of the first Science and Technology Symposium. Botswana Harnessing of Science and Technology for Development. University of Botswana and Technology Centre. Botswana. 2000.

10. Kasule, M. The occurrence of rotavirus in human stool samples and their molecular characterization in three health districts of Botswana. M.Sc (Applied Microbiology)Thesis, University of Botswana. 2001.

11. Cunliffe, M.A., Kilgore, P.E., Bresee, J.S., et al. Epidemiology of rotavirus diarrhoea in Africa: a review to assess the need for rotavirus immunisation. Bull. Wld.
Hlth. Org. 1998; 76:525-537.

12. Bishop, R.F. Natural history of rotavirus infection. In: Viral Infections of the Gastrointestinal Tract. A. Z. Kapikian (Ed.), 2nd Edition, Marcel Dekker, New York. 1994; 131-167.

13. Gomwalk, N.E., Gosham, L.T., and Umoh, U.J. Rotavirus gastroenteritis in paediatric diarrhoea in Jos, Nigeria. J. Trop. Pediat. 1990; 36:52-55.

14. Mahmood, D.A. and Feacham, R.G. Clinical and epidemiological characteristics of rotavirus and EPEC associated infantile diarrhoea in Brasrah, Iraq. J. Trop. Pediat. 1987; 33:319-325.

15. Perez-Schael, I., Gonzalez, R., Fernandez, R., et al. Epidemiological features of rotavirus infection in Carcas, Venezuela: Implications for rotavirus immunization programs. J. Med. Virol. 1999; 59:520-526.

16. Soares, C.C., Volotao, E.M., Alberquerque, M.C.M., et al. Prevalence of enteric adenoviruses among children with diarrhoea in four Brazilian cities. J. Clin. Virol. 2002; 23:171-177.

17. Grimwood, K., Carzino, R., Barnes, G.L., and Bishop, R.F. Patients with enteric adenovirus gastroenteritis admitted to an Australian paediatric teaching hospital from 1981 to 1992. J. Clin. Microb. 1995; 33:131-136.

18. Steele, A.D., Basetse, H.R., Blacklow, N.R., and Herrmann, J.E. Astrovirus infection in South Africa: a pilot study. Ann. trop. Paediat. 1998; 18:315-319.

19. Bon, F., Fascia, P., Dauvergne, M., et al. Prevalence of group A rotavirus, human calicivirus, astrovirus and type 40 and 41 infections among children with acute gastroenteritis in Dijon, France. J. Clin. Microb. 1999; 37:3055-3058

20. Kidd, A.H., Rosenblatt, A., Besselaar, T.G., et al. Characterisation of rotaviruses and subgroup $\mathrm{F}$ adenoviruses from acute summer gastroenteritis in South Africa. J. Med. Virol. 1986; 18:159-168

21. Saderi, H., Roustai, M.H., Sabahi, F., et al. Incidence of enteric adenovirus gastroenteritis in Iranian children. $J$. Clin. Virol. 2002; 34:1-5.

22. Maldonado, Y., Cantwell, M., Old, M., et al. Population based prevalence of symptomatic and asymptomatic astrovirus infection in rural Mayan Infants. J. Infect. Dis. 1998; 178:334-339.

23. Adrian, T., Wigand, R. and Ritcher, J. Gastroenteritis in infants, associated with a genome type of adenovirus 31 and with combined rotavirus and adenovirus 31 infection. Eur. J. Pediat. 1987; 146:38-40.

24. Wadell, G., Allard, A., Johansson, M., Svensson, M., and Uhnoo, I. Enteric Adenoviruses. In: Viral Infections of the gastrointestinal tract, 2nd Edn. A. Z. Kapkian (Ed.), Marcel Dekker, New York. 1994; 131-167.

25. Shetty, M., Brown, T.A., Kotian, M., and Shivananda, P.G. Viral diarrhoea in a rural coastal region of Karnataka India. J. Trop. Paediat. 1995; 41:301-303.

26. Stewien, K.E., Mos, E.N., Yanaguita, R.M. et al., Viral, bacterial and parasitic pathogens associated with severe diarrhoea in the city of Sao Paulo, Brazil. J. Diarrh. Dis. 1993; 11:148-152.

27. Palombo, E.A. and Bishop, R.F. Annual incidence, serotype distribution and genetic diversity of human astrovirus isolates from hospitalised patients in Melbourne, Australia. J. Clin. Microb. 1996; 34:1750-1753.

28. Dennehy, P.H., Nelson, S.M., Spangenberger, S., et al. A Prospective case-control study of the role of astrovirus in acute diarrhoea among hospitalised children. J. Infect. Dis. 2001; 184:10-15.

29. Lee, T.W. and Kurtz, J.B. Prevalence of human astrovirus serotypes in the Oxford region, 1976-1992, with evidence for two new serotypes. Epidem. Infect. 1994; 112:187-193. 